\title{
Chronic thromboembolic pulmonary hypertension: role of medical therapy
}

\author{
Joanna Pepke-Zaba*, Pavel Jansa\#, Nick H. Kim, \\ Robert Naeije ${ }^{+}$and Gerald Simonneau ${ }^{\S}$
}

ABSTRACT: Chronic thromboembolic pulmonary hypertension (CTEPH) is a progressive disease with poor prognosis if not treated. The treatment of choice is surgery with pulmonary endarterectomy. However, a significant percentage of patients are deemed non-operable due to distal distribution of the disease and arteriopathy in the non-occluded areas that is indistinguishable from pulmonary arterial hypertension (PAH). The overlap in clinical presentation, pathological features and pathogenesis between $\mathrm{PAH}$ and CTEPH provides a compelling rationale for exploring the efficacy of PAH-targeted therapies in CTEPH. These therapies are often considered for non-operable patients and are also used in operable patients as a bridge to surgery or as post-pulmonary endarterectomy therapy for persistent pulmonary hypertension, despite the fact they are not licensed for CTEPH.

Two randomised clinical trials have been performed in non-operable CTEPH patients. The BENEFiT study, with the endothelin receptor antagonist bosentan, did not show improvement in walking distance. Recently, the CHEST-1 trial, with the soluble guanylate cyclase stimulator riociguat, met study end-point and demonstrated significant improvement in walking distance in patients with non-operable CTEPH.

There is an urgent need for more randomised clinical trials designed to clarify whether administration of PAH-targeted therapies improves clinically meaningful end-points in various CTEPH populations.

KEYWORDS: Drug therapy, pulmonary arterial hypertension, pulmonary vasculature, thromboembolism, vascular remodelling

hronic thromboembolic pulmonary hypertension (CTEPH) and pulmonary arterial hypertension $(\mathrm{PAH})$ are dyspnoea-fatigue syndromes caused by an increase in pulmonary vascular resistance (PVR) leading to right ventricular failure [1]. CTEPH and PAH have historically been associated with a poor prognosis, but in the majority of cases, CTEPH can now be cured surgically with pulmonary endarterectomy (PEA) [2].
CTEPH is a rare disease with an estimated incidence of 2,500 new cases per year in the USA [3]. Recent follow-up studies in patients presenting with acute pulmonary embolism suggest that CTEPH develops in $0.6-9 \%$ of patients having experienced an acute pulmonary embolism [4-8]. However, a significant number of CTEPH patients $(25-75 \%)$ have no history of acute pulmonary embolism [9-12]. Therefore, the true incidence of CTEPH is likely to be underestimated by studies

Previous articles in this Series: No. 1: Delcroix M, Vonk-Noordegraaf A, Fadel E, et al. Vascular and right ventricular remodelling in chronic thromboembolic pulmonary hypertension. Eur Respir J 2013; 41: 224-232. No. 2: Lang IM, Pesavento R, Bonderman D, et al. Risk factors and basic mechanisms of chronic thromboembolic pulmonary hypertension: a current understanding. Eur Respir J 2013; 41: 462-468. No. 3: Jenkins DP, Madani M, Mayer E, et al. Surgical treatment of chronic thromboembolic pulmonary hypertension. Eur Respir J 2013; 41: 735-742.

AFFILIATIONS

*Pulmonary Vascular Diseases Unit, Papworth Hospital, Cambridge, UK. ${ }^{*}$ Clinical Dept of Cardiology and Angiology, Charles University, 1st Faculty of Medicine, 2nd Medical Dept, Prague, Czech Republic. -Pulmonary Vascular Medicine, UC San Diego, La Jolla, CA, USA. +Dept of Physiology, Université Libre de Bruxelles, Brussels, Belgium. ${ }^{\S}$ Centre National de Référence de I'Hypertension Artérielle Pulmonaire, Paris-Sud University, Paris, France.

CORRESPONDENCE

J. Pepke-Zaba

Pulmonary Vascular Diseases Unit Papworth Hospital

Cambridge CB23 3RE UK E-mail: joanna.pepkezaba@ papworth.nhs.uk

Received:

Dec 132012

Accepted:

Dec 192012 
that only follow patients after an acute pulmonary embolism [13]. A prospective cohort study by CONDLIFFE et al. [14] involving all UK pulmonary hypertension $(\mathrm{PH})$ centres reported an incidence of 1.75 cases per million per year in 2006. Recent UK data show that CTEPH was diagnosed in $14 \%$ of incident cases referred to designated national PH centres in 2010-2011. The prevalence standardised for age and sex (per million and per year) is 16.6 in England, 14.3 in Scotland and 12.3 in Wales [15]. These data suggest that CTEPH may be more common than previously thought.

CTEPH results from the obstruction of the pulmonary vascular bed by non-resolving thromboemboli, which may completely occlude the lumen or form different grades of stenosis, webs and bands. CTEPH is often described as a two-compartment disease including mechanical intraluminal obstructions and a variable degree of arteriopathy in non-occluded areas that is indistinguishable from PAH [16]. CTEPH patients often display severe PH that cannot be fully explained by the degree of pulmonary vascular obstruction visible on imaging. In these cases, the increased PVR may be due to distal obstructive thrombotic lesions situated beyond the subsegmental level, but also to vasculopathy present at the pre-capillary level. These distal lesions, which are difficult to treat by surgical disobliteration with PEA, may be responsible for out of proportion elevated PVR prior to surgery and for persisting or residual $\mathrm{PH}$ following PEA. Patients presenting with a distal disease that is not suitable for surgery are often considered for management with PAH-targeted therapies [17-19] despite the fact these medications are not approved for the treatment of CTEPH.

The present article will focus on recent developments in the pharmacological treatment of CTEPH and review the evidence supporting the use of PAH-targeted therapies in CTEPH.

\section{OVERLAP IN CLINICAL AND PATHOLOGICAL PRESENTATION BETWEEN PAH AND CTEPH}

The diagnosis of $\mathrm{PAH}$ and CTEPH requires a common methodical step-by-step work-up to elucidate the cause of $\mathrm{PH}$ [20]. However, physical findings, chest roentgenograms, electrocardiograms, echocardiograms and pulmonary function tests may not differentiate the two conditions [21]. The differential diagnosis between $\mathrm{CTEPH}$ and $\mathrm{PAH}$ is made from imaging investigations: ventilation/perfusion scanning, angiographycomputed tomography and pulmonary angiography. A correct diagnosis of CTEPH or PAH is of crucial therapeutic relevance as PAH can be improved by PAH-targeted therapies, whereas $\mathrm{CTEPH}$ is potentially cured by PEA.

The management of CTEPH can be complicated by the presence of small vessel disease, mimicking the histopathological changes observed in PAH. There appear to be three categories of small vessel disease that may contribute to CTEPH: 1) obstruction of small subsegmental and more distal arteries that are out of reach for the PEA surgeon; 2) pulmonary arteriopathy of small muscular arteries and arterioles distal to unobstructed elastic arteries; and 3) pulmonary arteriopathy of small muscular arteries and arterioles distal to obstructed elastic arteries. Histopathology of the lung tissue taken from patients with CTEPH reveals plexiform lesions and intimal thickening of the small pulmonary arteries and arterioles appearing very similar to those seen in other forms of severe non-thromboembolic PAH [22].

PEA is the treatment of choice for CTEPH [23]; however, only about $60 \%$ of the presenting patients will have the operation and $10-15 \%$ of the operated patients will be left with clinically significant $\mathrm{PH}[2,21,23,24]$. In these patients, peripheral arteriolar remodelling is a cause of severe morbidity or even mortality after an otherwise successful surgery.

The similarities between CTEPH and PAH in both clinical and pathological presentation suggest that $\mathrm{PAH}$-targeted therapies may be of benefit in selected patients with CTEPH, especially those with substantial small-vessel arteriopathy.

\section{EVIDENCE FOR THE PRESENCE OF SIMILAR THERAPEUTIC PATHWAYS IN CTEPH AND PAH}

Alterations in several signalling pathways contribute to the development of PH. Three of these pathways, the endothelin, nitric oxide and prostacyclin pathways, represent the targets of the current therapeutic management of PAH. Studies examining the pathophysiology of CTEPH in animal and human models have provided a rationale for the use of endothelin receptor antagonists. It is known that endothelin-1 (ET-1) is a potent endogenous vasoconstrictor and that endothelial signalling pathway components are up-regulated in CTEPH [25]. Elevated ET-1 levels have been reported in animal models of CTEPH and treatment with bosentan, a dual endothelin receptor antagonist, prevented pulmonary artery remodelling in a canine model of CTEPH $[26,27]$.

REESINK et al. [28] have investigated the correlation between ET-1 levels and haemodynamics after PEA. ET-1 levels were increased in 35 CTEPH patients $\left(1.62 \pm 0.21 \mathrm{pg} \cdot \mathrm{mL}^{-1}\right)$ compared with healthy controls $\left(0.75 \pm 0.06 \mathrm{pg} \cdot \mathrm{mL}^{-1} ; \mathrm{p}<0.02\right)$. ET- 1 levels correlated with mean pulmonary arterial hypertension (mPAP; $\mathrm{r}=0.70)$, cardiac index $(\mathrm{r}=-0.76)$, total pulmonary resistance $(\mathrm{TPR} ; \mathrm{r}=0.72)$, mixed venous oxygen saturation $(\mathrm{r}=-0.87)$, and 6-min walking distance (6MWD; $\mathrm{r}=-0.59 ; \mathrm{p}<0.005 ; \mathrm{n}=23$ ). Three months after PEA, ET-1 levels had decreased $(\mathrm{p}<0.002)$. Pre-operative ET-1 levels were higher in patients with poor post-operative outcome and were correlated with haemodynamic outcome after PEA (mPAP: $r=0.67 ; \mathrm{p}<0.0001$ ). These results suggest that $\mathrm{CTEPH}$ and $\mathrm{PAH}$ share a common pathophysiological mechanism involving endothelin.

The contribution of the nitric oxide and prostacyclin pathways to the development of PAH is well documented but less is known about the involvement of these mechanisms in CTEPH.

\section{CURRENT MEDICAL THERAPY AND CLINICAL EVIDENCE FOR THE MANAGEMENT OF CTEPH WITH PAH-TARGETED THERAPIES}

Before discussing the rationale and data supporting medical therapy in CTEPH, the importance of early referral to a PEA centre has to be emphasised. In the absence of a consensus definition for operability [29], the decision to operate hinges on the correlation between the anatomic location of the disease and the increase in PVR, but it is also dependent on centre expertise. An experienced surgeon may operate on cases some would deem non-operable and haemodynamics may be improved far beyond what can be expected with PAH-targeted therapies. With operable CTEPH patients, surgery can improve 
PVR by $80 \%$ [24] with a 5 -year survival of $90 \%$ [30]. In contrast, medical therapy will improve PVR by $25 \%$ [19] with a 3-year survival of 70\% [14]. Thus, all patients with CTEPH should be referred to an expert PEA centre to be assessed for operability.

In the following paragraphs, we review current medical treatment and discuss the evidence supporting the management of CTEPH patients with PAH-targeted therapies.

\section{Anticoagulation}

All patients with CTEPH should receive lifelong anticoagulation adjusted to a normalised target ratio between 2.0 and 3.0. The rationale is to prevent in situ pulmonary artery thrombosis and recurrent venous thromboembolism. When the disease is fully established, significant regression of pulmonary hypertension from anticoagulation is not expected.

\section{Medical therapy in non-operable CTEPH and post-operative persistent $\mathbf{P H}$}

The effects of PAH-targeted therapies have been investigated in CTEPH patients with a distal lesion distribution caused by surgically inaccessible obstructions or by arteriopathy of distal small muscular arteries. In the international registry on CTEPH [12], which includes 679 patients from 27 centres, 247 (36.4\%) patients were deemed non-operable and $16.7 \%$ of the operated patients had residual $\mathrm{PH}$ at the end of their intensive care stay [2]. Persistent PH after PEA may be caused by a surgically inaccessible obstruction and/or a small vessel arteriopathy. Increasing evidence suggests that the PAH-targeted therapies empirically used in patients with severe non-operable CTEPH may benefit these patients with suboptimal responses to surgery.

Several open-label studies have been performed with prostanoids, endothelin receptor antagonists, phosphodiesterase-5 inhibitors and soluble guanylate cyclase (sGC) stimulators in patients with non-operable CTEPH and/or with persistent $\mathrm{PH}$ after PEA.

\section{Prostanoids}

\section{Epoprostenol}

In a retrospective study including patients with non-operable CTEPH $(n=16)$ and idiopathic PAH (IPAH) $(n=16)$ treated with i.v. epoprostenol and followed-up for 1 year, SCELSI et al. [31] reported a significant improvement in New York Heart Association (NYHA) functional class and exercise capacity in both groups. There was no difference in outcomes or adverse events between IPAH and CTEPH patients.

In a French retrospective cohort of non-operable CTEPH patients $(n=27)$ treated with i.v. epoprostenol and followed for a mean duration of 20 months, there was a significant increase in exercise capacity and cardiac index and a decrease in NYHA functional class, PVR and mPAP [32]. At the end of the study, only nine patients were still on epoprostenol, five had been transplanted and 13 had died. The 2-year survival rate was $59 \%$. Prospective and larger studies are needed to ascertain the effects of epoprostenol in non-operable CTEPH.

\section{lloprost}

A post hoc subgroup analysis from a double blind, placebocontrolled PH study (the AIR trial [33]), compared 33 CTEPH patients treated with inhaled iloprost, with 24 receiving placebo. Patients on iloprost had improved quality of life and dyspnoea scores but did not increase their 6MWD when compared with patients who had received the placebo.

\section{Beraprost}

In a trial reported by ONO et al. [34], the effects of conventional treatment with $(n=20)$ and without $(n=23)$ beraprost were compared in patients with non-operable CTEPH. There was a significant decrease in TPR and an improvement in NYHA functional class in the beraprost group. After a mean follow-up period of 58 months, there were fewer deaths in this group compared with conventional treatment.

\section{Treprostinil}

A retrospective study compared the effect of subcutaneous treprostinil in patients with PAH $(n=99)$ and non-operable CTEPH $(n=23)$. After a mean follow-up of 26 months, significant improvements in NYHA functional class, exercise capacity and survival compared with historical cohorts were seen in both groups [35]. In a subsequent case-control study, patients with non-operable CTEPH $(n=19)$ or persistent PH after PEA $(n=6)$, treated with subcutaneous treprostinil, were compared with 31 matched conventionally treated patients. Treprostinil induced significant improvements in exercise capacity, NYHA functional class, plasma N-terminal pro-brain natriuretic peptide (NTproBNP) levels, PVR, CI and survival [36].

\section{Endothelin receptor antagonists}

\section{Bosentan}

HOEPER et al. [37] performed a prospective open label multicentre study including 19 non-operable CTEPH patients treated with bosentan. After 3 months, there was a significant decrease in PVR (-303 dyn $\left.\cdot \mathrm{s}^{\cdot} \cdot \mathrm{cm}^{-5} ; \mathrm{p}<0.001\right)$ and NT-proBNP $\left(-716 \mathrm{pg} \cdot \mathrm{mL}^{-1} ; \mathrm{p}=0.027\right)$ and an improvement in $6 \mathrm{MWD}(+73 \mathrm{~m}$; $\mathrm{p}=0.009$ ). There was no significant change in NYHA functional class or peak oxygen uptake. At the same time, BONDERMAN et al. [38] reported on a series of 16 non-operable CTEPH patients treated for 6 months with bosentan: NYHA functional class improved by one class in 11 patients, and 6MWD increased from $299 \pm 131 \mathrm{~m}$ at baseline to $391 \pm 110 \mathrm{~m}$ at 6 months $(\mathrm{p}=0.01$ ). HuGHES et al. [39] investigated the efficacy and safety of bosentan in a European multicentre, open label retrospective study including patients with non-operable CTEPH $(n=39)$ or persistent PH after PEA $(n=8)$. After 4 months of treatment, $6 \mathrm{MWD}$ had increased $(+49 \mathrm{~m} ; \mathrm{p}<0.001)$ and $17 \%$ of patients had an improvement in NYHA functional class. By 1 year, two patients had died and two had deteriorated, requiring prostanoid treatment. The improvement in exercise capacity was maintained (+52 $\mathrm{m}$ versus baseline; $\mathrm{p}<0.001)$. During follow-up, 28 patients had a repeat right heart catheterisation. In these patients, there was a significant increase in cardiac index $\left(+0.2 \mathrm{~L} \cdot \mathrm{min}^{-1} \cdot \mathrm{m}^{-2}\right.$; $\mathrm{p}=0.004)$ and decrease in TPR $\left(-138 \mathrm{dyn} \cdot \mathrm{s} \cdot \mathrm{cm}^{-5} ; \mathrm{p}=0.003\right)$.

One large randomised clinical trial has been performed in patients with non-operable CTEPH: the BENEFiT (Bosentan Effects in iNopErable Forms of chronIc Thromboembolic pulmonary hypertension) study $(\mathrm{n}=157)$ [19]. 157 patients were enrolled and randomised: 80 to placebo, 77 to bosentan. Although there was a significant $24 \%$ reduction in PVR after 16 weeks of treatment $\left(-146 \mathrm{dyn} \cdot \mathrm{s} \cdot \mathrm{cm}^{-5} ; \mathrm{p}<0.0001\right)$ in one of the co-primary end-points, there was no change in the 6MWD 
$(+2.2 \mathrm{~m} ; \mathrm{p}=0.5449)$. Significant changes were also reported in secondary end-points: cardiac index $\left(+0.3 \mathrm{~L} \cdot \mathrm{min}^{-1} \cdot \mathrm{m}^{-2}\right.$; $\mathrm{p}=0.0007)$ and NT-proBNP $\left(-622 \mathrm{pg} \cdot \mathrm{mL}^{-1} ; \mathrm{p}=0.0034\right)$.

This study demonstrated a positive treatment effect of bosentan on haemodynamics in this patient population but no improvement was observed in exercise capacity.

\section{Phosphodiesterase type-5 inhibitors}

In two open label studies, patients with non-operable CTEPH were treated with sildenafil for 6 months $(n=12)$ [40] and 12 months $(n=104)$ [18]. In both studies, sildenafil was well tolerated and there were significant improvements in both exercise capacity and haemodynamics. A small randomised, placebo-controlled pilot trial with sildenafil reported by SUNTHARALINGAM et al. [41] enrolled 19 patients with nonoperable CTEPH or persistent PH after PEA. The primary endpoint (change in 6MWD at 12 weeks) was not met $(+17.5 \mathrm{~m}$ versus placebo) possibly because the trial was small and underpowered but significant improvements in NYHA functional class and PVR $\left(-197\right.$ dyn $\left.\cdot \mathrm{s} \cdot \mathrm{cm}^{-5} ; \mathrm{p}<0.05\right)$ were reported in the sildenafil group. At the end of the trial, patients could transfer to open label sildenafil. After 1 year of sildenafil treatment, patients had improved exercise capacity, haemodynamics and NT-proBNP levels compared with baseline values.

Together these studies suggest that sildenafil might be beneficial in CTEPH but larger, multicentre, placebo-controlled trials are needed to confirm these findings.

\section{Combination therapy}

Further studies are required to determine whether the benefits of combination therapy seen in PAH extend to CTEPH.

\section{New compounds}

Riociguat, a new oral sGC stimulator, has shown promising results in the treatment of PAH [42]. In a 12-week, multicentre, open-label, uncontrolled phase II study, a median 6MWD increase of $55 \mathrm{~m}$ from baseline $(\mathrm{p}<0.0001)$ was observed in CTEPH patients treated with riociguat [43].

GHOFRANI et al. [44] recently presented results from the phase III, multicentre, randomised clinical trial: the Chronic Thromboembolic Pulmonary Hypertension sGC-Stimulator Trial-1 (CHEST-1) to the American College of Chest Physicians in October 2012, in Atlanta, GA, USA. The CHEST-1 trial investigated the efficacy and safety of riociguat in patients with non-operable CTEPH $(n=263)$. Enrolled patients were assessed by an independent adjudication committee as non-operable, or had persisting or recurrent $\mathrm{PH}$ after PEA. The trial met its primary end-point, demonstrating a statistically significant improvement in 6MWD $(+46 \mathrm{~m}$; p $<0.0001)$ in patients treated for 16 weeks with riocuguat compared with placebo. Riociguat also showed statistically significant improvements in secondary end-points including PVR, NT-proBNP and NYHA functional class. The long term safety and efficacy of riociguat needs to be evaluated, but early results are promising.

\section{Medical therapy in operable CTEPH: bridging to PEA}

There is a significant number of operable CTEPH patients who are haemodynamically unstable in the pre-operative period, making PEA a high-risk procedure. These patients include those in NYHA functional class IV, those with $\mathrm{mPAP}>50 \mathrm{mmHg}$, cardiac index $<2 \mathrm{~L} \cdot \mathrm{min}^{-1} \cdot \mathrm{m}^{-2}$ and/or PVR $>1200 \mathrm{dyn} \cdot \mathrm{s} \cdot \mathrm{cm}^{-5}$. The operative mortality has been reported previously to be less than $5 \%$ when PVR is below 900 dyn $\cdot \mathrm{s}^{\cdot} \mathrm{cm}^{-5}$ but greater than $20 \%$ when PVR is above $1200 \mathrm{dyn} \cdot \mathrm{s}^{\cdot} \mathrm{cm}^{-5}$ [24]. Whether improving haemodynamics with pre-operative PAH treatment improves surgical outcome is unknown and remains largely speculative.

The concept of introducing medical therapy as a "therapeutic bridge" between diagnosis and PEA was introduced by NAGAYA et al. [45]. These authors followed 12 patients with severe CTEPH treated with continuous i.v. epoprostenol for 7 weeks prior to PEA. Epoprostenol significantly decreased pre-operative PVR by $28 \%$ and increased CI by 35\%. BRESSER et al. [46] retrospectively analysed nine PEA candidates treated with continuous i.v. epoprostenol before surgery. Substantial improvements in cardiac index, $\mathrm{MPAP}$ and TPR were seen in all patients after PEA but the impact on post-PEA morbidity and mortality could not be established. REESINK et al. [47] analysed pulmonary haemodynamics and functional capacity in 25 PEA candidates treated with $(n=13)$ or without bosentan $(n=12)$. After 16 weeks of treatment, significant improvements were observed in TPR, MPAP, and 6MWD, in the bosentan group compared with the control group, although post-PEA outcomes were similar in both groups.

The outcomes of these studies should be interpreted with caution. The studies of NAGAYA et al. [45] and BRESSER et al. [46] are based on small patient populations participating in retrospective and uncontrolled studies. The study presented by REESINK et al. [47] was prospective and randomised, but included a limited number of patients. More recently, JENSEN et al. [48] retrospectively analysed the medical treatment of the CTEPH patients referred to their institution for PEA between 2005 and 2007. They observed that the use of PAH-targeted therapies before surgery had significantly increased from $19.9 \%$ in 2005 to $37 \%$ in 2007 , but was not associated with significant improvement in pre-operative pulmonary haemodynamics and post-operative outcome. In the recent international CTEPH registry [12], $28.3 \%$ of the operable CTEPH patients were prescribed at least one $\mathrm{PAH}$-targeted therapy at diagnosis. It is possible that this increased use of medications in operable patients could delay patients' referral for PEA. The optimal duration of a therapeutic bridge to PEA is still not clearly defined. Selection of suitable candidates for bridging therapy should be carefully carried out in expert centres.

In summary, a substantial number of patients (operable and non-operable) are currently being treated with off-label treatments. The results from the international CTEPH registry have shown that nearly $38 \%$ of the CTEPH patients $(54 \%$ nonoperable and $28 \%$ operable) are treated with at least one PAHtargeted therapy at diagnosis [12].

Most of the studies investigating the use of PAH-targeted therapies in the management of patients with distal CTEPH show beneficial effects. However, these results come from predominantly observational uncontrolled studies and should be interpreted with caution. A post hoc analysis from the AIR study demonstrated no improvement in 6MWD with inhaled iloprost [33]. In both randomised clinical trials performed in 
CTEPH patients, the BENEFiT study with bosentan [19] and the CHEST-1 study with riociguat [44], significant improvements in haemodynamics (PVR) were reported after 16 weeks of treatment but improvement in exercise capacity was only observed with riociguat.

The lack of effect of bosentan on 6MWD in the BENEFiT trial was surprising, as significant improvements in haemodynamics and NT-proBNP levels were observed and several open label studies with bosentan had previously reported improved exercise capacity [37-39].

However, the recently presented CHEST-1 trial results could provide further evidence to support medical treatment in selected non-operable CTEPH patients [44]. Also, there is no expert agreement on the criteria defining operability; therefore, it is difficult to characterise the CTEPH patients who might benefit from medical therapies. The results from the CHEST-1 trial with riociguat highlight the need for a careful description of the patients who may benefit from PAH-targeted therapies and for meaningful end-points, which are specific for CTEPH [44], e.g. time to clinical worsening and the number of patients being successfully bridged to PEA due to substantial improvement in PVR and lower operative concerns.

\section{SAFETY ASPECTS}

Disease comorbidities (e.g. chronic obstructive pulmonary disease and cardiac disease) are important factors in the choice of an appropriate medical therapy for patients with CTEPH. These patients are generally older than patients with $\mathrm{PAH}$, and tend to have more frequent and more severe comorbidities. There are currently no studies specifically reporting on the safety/tolerability of PAH-specific therapies in $\mathrm{CTEPH}$, although published trials and observational studies suggest no unexpected adverse events or safety issues for up to 1 year of treatment.

\section{SURVIVAL AND LONG-TERM OUTCOME}

It is generally accepted that most patients with CTEPH have a progressive disease [21]. Survival of CTEPH patients before the advent of modern treatments including PEA was poor. LEWCZUK et al. [49] reported a 3-year survival rate of $12 \%$ when mPAP was greater than $30 \mathrm{mmHg}$ at diagnosis and RIEDEL et al. [50] a 5-year survival rate of $10 \%$ when the mPAP was greater than $50 \mathrm{mmHg}$.

In a study of 35 patients with distal CTEPH managed in the modern era, SUNTHARALINGAM et al. [51] reported the 1- and 3year survival rates to be $77 \%$ and $53 \%$, respectively. Recently, CONDLIFFE et al. [14] described the follow-up of CTEPH patients in the UK national cohort; 148 (32\%) patients had a distal nonoperable disease and despite the mPAP being $49 \mathrm{mmHg}$, the 1year and 3-year survival rates were $83 \%$ and $76 \%$, respectively ( $90 \%$ of the patients of this cohort were treated with PAHspecific treatments). The 5-year survival rate of patients with persistent $\mathrm{PH}$ after PEA has been reported to be $90 \%$ (25\% of the patients were treated with $\mathrm{PAH}$-specific treatments) [30]. Prospective data on the effects of PAH-specific therapies on the long-term outcome of CTEPH patients are currently being collected in the international CTEPH registry [52] and are expected to contribute to the assessment of the usefulness of PAH-specific therapies in the management of CTEPH patients.

\section{CONCLUSIONS}

PEA is considered as the first choice of treatment for selected CTEPH patients but there is no expert agreement on the criteria defining operability; therefore, it is difficult to characterise the CTEPH patients who might benefit from medical therapies. The surgery can be a cure for some patients but may also lead to persistent $\mathrm{PH}$ in others. In patients deemed non-operable and in those with persistent $\mathrm{PH}$ following PEA, the similarities in pathobiology between $\mathrm{CTEPH}$ and $\mathrm{PAH}$ suggest that PAHtargeted therapies may play a role. There is as yet no scientific evidence to make such a recommendation and it is possible that the small vessel component of CTEPH may not mimic PAH when it comes to medical therapy with the current agents. There are no PAH targeted therapies approved for CTEPH currently and the status of riociguat is pending. However, the recently presented CHEST-1 trial results could provide further evidence to support medical treatment in selected non-operable CTEPH patients. Although the results of this trial are encouraging, there remain numerous unanswered questions and unmet needs regarding the role of medical therapy in CTEPH. Long term data are needed to better define and understand the benefits of PAH targeted therapies in CTEPH. Accordingly, we need to continue exploring and better defining the role of PAH targeted therapies, operability definition, and clinically meaningful end-points in CTEPH.

\section{STATEMENT OF INTEREST}

Conflict of interest information can be found alongside the online version of this article at www.erj.ersjournals.com

\section{REFERENCES}

1 McLaughlin VV, Archer SL, Badesch DB, et al. ACCF/AHA 2009 expert consensus document on pulmonary hypertension: a report of the American College of Cardiology Foundation Task Force on Expert Consensus Documents and the American Heart Association: developed in collaboration with the American College of Chest Physicians, American Thoracic Society, Inc., and the Pulmonary Hypertension Association. Circulation 2009; 119: 2250-2294.

2 Mayer E, Jenkins D, Lindner J, et al. Surgical management and outcome of patients with chronic thromboembolic pulmonary hypertension: results from an international prospective registry. J Thorac Cardiovasc Surg 2011; 141: 702-710.

3 Fedullo PF, Auger WR, Kerr KM, et al. Chronic thromboembolic pulmonary hypertension. N Engl J Med 2001; 345: 1465-1472.

4 Ribeiro A, Lindmarker P, Johnsson H, et al. Pulmonary embolism: one-year follow-up with echocardiography doppler and five-year survival analysis. Circulation 1999; 99: 1325-1330.

5 Becattini C, Agnelli G, Pesavento R, et al. Incidence of chronic thromboembolic pulmonary hypertension after a first episode of pulmonary embolism. Chest 2006; 130: 172-175.

6 Miniati M, Monti S, Bottai M, et al. Survival and restoration of pulmonary perfusion in a long-term follow-up of patients after acute pulmonary embolism. Medicine (Baltimore) 2006; 85: 253-262.

7 Pengo V, Lensing $\mathrm{AW}$, Prins $\mathrm{MH}$, et al. Incidence of chronic thromboembolic pulmonary hypertension after pulmonary embolism. N Engl J Med 2004; 350: 2257-2264.

8 Klok FA, van Kralingen KW, van Dijk AP, et al. Prospective cardiopulmonary screening program to detect chronic thromboembolic pulmonary hypertension in patients after acute pulmonary embolism. Haematologica 2010; 95: 970-975.

9 Bonderman D, Jakowitsch J, Adlbrecht C, et al. Medical conditions increasing the risk of chronic thromboembolic pulmonary hypertension. Thromb Haemost 2005; 93: 512-516. 
10 Bonderman D, Wilkens H, Wakounig S, et al. Risk factors for chronic thromboembolic pulmonary hypertension. Eur Respir J 2009; 33: 325-331.

11 Condliffe R, Kiely DG, Gibbs JS, et al. Prognostic and aetiological factors in chronic thromboembolic pulmonary hypertension. Eur Respir J 2009; 33: 332-338.

12 Pepke-Zaba J, Delcroix M, Lang I, et al. Chronic thromboembolic pulmonary hypertension (CTEPH): results from an international prospective registry. Circulation 2011; 124: 1973-1981.

13 Lang IM. Chronic thromboembolic pulmonary hypertension-not so rare after all. N Engl J Med 2004; 350: 2236-2238.

14 Condliffe R, Kiely DG, Gibbs JS, et al. Improved outcomes in medically and surgically treated chronic thromboembolic pulmonary hypertension. Am J Respir Crit Care Med 2008; 177: 1122-1127.

15 The NHS Information Centre. National Audit of Pulmonary Hypertension 2011. Leeds, NHS Information Centre, 2011. Available from: https://catalogue.ic.nhs.uk/publications/clinical/ heart/nati-pulm-hype-audi-2011/nati-pulm-hype-audi-2011-ref.pdf

16 Moser KM, Auger WR, Fedullo PF. Chronic major-vessel thromboembolic pulmonary hypertension. Circulation 1990; 81: 1735-1743.

17 Hill NS, Preston IR, Roberts KE. Inoperable chronic thromboembolic pulmonary hypertension: treatable with medical therapy. Chest 2008; 134: 221-223.

18 Reichenberger F, Voswinckel R, Enke B, et al. Long-term treatment with sildenafil in chronic thromboembolic pulmonary hypertension. Eur Respir J 2007; 30: 922-927.

19 Jais X, D'Armini AM, Jansa P, et al. Bosentan for treatment of inoperable chronic thromboembolic pulmonary hypertension: BENEFiT (Bosentan Effects in iNopErable Forms of chronIc Thromboembolic pulmonary hypertension), a randomized, placebo-controlled trial. J Am Coll Cardiol 2008; 52: 2127-2134.

20 McLaughlin VV, Archer SL, Badesch DB, et al. ACCF/AHA 2009 expert consensus document on pulmonary hypertension a report of the American College of Cardiology Foundation Task Force on Expert Consensus Documents and the American Heart Association developed in collaboration with the American College of Chest Physicians; American Thoracic Society, Inc.; and the Pulmonary Hypertension Association. J Am Coll Cardiol 2009; 53: 1573-1619.

21 Hoeper MM, Mayer E, Simonneau G, et al. Chronic thromboembolic pulmonary hypertension. Circulation 2006; 113: 2011-2020.

22 Yi ES, Kim H, Ahn H, et al. Distribution of obstructive intimal lesions and their cellular phenotypes in chronic pulmonary hypertension. A morphometric and immunohistochemical study. Am J Respir Crit Care Med 2000; 162: 1577-1586.

23 Auger WR, Kerr KM, Kim NH, et al. Chronic thromboembolic pulmonary hypertension. Cardiol Clin 2004; 22: 453-466.

24 Dartevelle P, Fadel E, Mussot S, et al. Chronic thromboembolic pulmonary hypertension. Eur Respir J 2004; 23: 637-648.

25 Bauer M, Wilkens H, Langer F, et al. Selective upregulation of endothelin B receptor gene expression in severe pulmonary hypertension. Circulation 2002; 105: 1034-1036.

26 Kim H, Yung GL, Marsh JJ, et al. Endothelin mediates pulmonary vascular remodelling in a canine model of chronic embolic pulmonary hypertension. Eur Respir J 2000; 15: 640-648.

27 Kim H, Yung GL, Marsh JJ, et al. Pulmonary vascular remodeling distal to pulmonary artery ligation is accompanied by upregulation of endothelin receptors and nitric oxide synthase. Exp Lung Res 2000; 26: 287-301.

28 Reesink HJ, Meijer RC, Lutter R, et al. Hemodynamic and clinical correlates of endothelin- 1 in chronic thromboembolic pulmonary hypertension. Circ J 2006; 70: 1058-1063.

29 Jenkins D, Madani M, Mayer E, et al. Surgical treatment of chronic thromboembolic hypertension. Eur Respir J 2013; 41: 735-742.

30 Freed DH, Thomson BM, Berman M, et al. Survival after pulmonary thromboendarterectomy: effect of residual pulmonary hypertension. J Thorac Cardiovasc Surg 2011; 141: 383-387.
31 Scelsi L, Ghio S, Campana C, et al. Epoprostenol in chronic thromboembolic pulmonary hypertension with distal lesions. Ital Heart J 2004; 5: 618-623.

32 Cabrol S, Souza R, Jais X, et al. Intravenous epoprostenol in inoperable chronic thromboembolic pulmonary hypertension. $J$ Heart Lung Transplant 2007; 26: 357-362.

33 Olschewski H, Simonneau G, Galie N, et al. Inhaled iloprost for severe pulmonary hypertension. N Engl J Med 2002; 347: 322-329.

34 Ono F, Nagaya N, Okumura H, et al. Effect of orally active prostacyclin analogue on survival in patients with chronic thromboembolic pulmonary hypertension without major vessel obstruction. Chest 2003; 123: 1583-1588.

35 Lang I, Gomez-Sanchez M, Kneussl M, et al. Efficacy of long-term subcutaneous treprostinil sodium therapy in pulmonary hypertension. Chest 2006; 129: 1636-1643.

36 Skoro-Sajer N, Bonderman D, Wiesbauer F, et al. Treprostinil for severe inoperable chronic thromboembolic pulmonary hypertension. J Thromb Haemost 2007; 5: 483-489.

37 Hoeper MM, Kramm T, Wilkens H, et al. Bosentan therapy for inoperable chronic thromboembolic pulmonary hypertension. Chest 2005; 128: 2363-2367.

38 Bonderman D, Nowotny R, Skoro-Sajer N, et al. Bosentan therapy for inoperable chronic thromboembolic pulmonary hypertension. Chest 2005; 128: 2599-2603.

39 Hughes RJ, Jais X, Bonderman D, et al. The efficacy of bosentan in inoperable chronic thromboembolic pulmonary hypertension: a 1year follow-up study. Eur Respir J 2006; 28: 138-143.

40 Ghofrani HA, Schermuly RT, Rose F, et al. Sildenafil for long-term treatment of nonoperable chronic thromboembolic pulmonary hypertension. Am J Respir Crit Care Med 2003; 167: 1139-1141.

41 Suntharalingam J, Treacy CM, Doughty NJ, et al. Long-term use of sildenafil in inoperable chronic thromboembolic pulmonary hypertension. Chest 2008; 134: 229-236.

42 Belik J. Riociguat, an oral soluble guanylate cyclase stimulator for the treatment of pulmonary hypertension. Curr Opin Investig Drugs 2009; 10: 971-979.

43 Ghofrani HA, Hoeper MM, Halank M, et al. Riociguat for chronic thromboembolic pulmonary hypertension and pulmonary arterial hypertension: a phase II study. Eur Respir J 2010; 36: 792-799.

44 Ghofrani H, Grimminger F, Hoeper M, et al. Riociguat for the treatment of inoperable chronic thromboembolic pulmonary hypertension: a randomized, double-blind, placebo-controlled study (CHEST-1). Chest 2012; 142: Suppl., 1023A.

45 Nagaya N, Sasaki N, Ando M, et al. Prostacyclin therapy before pulmonary thromboendarterectomy in patients with chronic thromboembolic pulmonary hypertension. Chest 2003; 123: 338-343.

46 Bresser P, Fedullo PF, Auger WR, et al. Continuous intravenous epoprostenol for chronic thromboembolic pulmonary hypertension. Eur Respir J 2004; 23: 595-600.

47 Reesink HJ, Surie S, Kloek JJ, et al. Bosentan as a bridge to pulmonary endarterectomy for chronic thromboembolic pulmonary hypertension. J Thorac Cardiovasc Surg 2010; 139: 85-91.

48 Jensen KW, Kerr KM, Fedullo PF, et al. Pulmonary hypertensive medical therapy in chronic thromboembolic pulmonary hypertension before pulmonary thromboendarterectomy. Circulation 2009; 120: $1248-1254$.

49 Lewczuk J, Piszko P, Jagas J, et al. Prognostic factors in medically treated patients with chronic pulmonary embolism. Chest 2001; 119: 818-823.

50 Riedel M, Stanek V, Widimsky J, et al. Longterm follow-up of patients with pulmonary thromboembolism. Late prognosis and evolution of hemodynamic and respiratory data. Chest 1982; 81: 151-158.

51 Suntharalingam J, Machado RD, Sharples LD, et al. Demographic features, BMPR2 status and outcomes in distal chronic thromboembolic pulmonary hypertension. Thorax 2007; 62: 617-622.

52 International CTEPH Association. CTEPH Registry. www.ctephassociation.org/registries/ Date last accessed: February 6, 2013. 